Check for updates

Cite this: RSC Adv., 2018, 8, 22053

Received 24th April 2018

Accepted 5th June 2018

DOI: $10.1039 / \mathrm{c} 8 \mathrm{ra03514h}$

rsc.li/rsc-advances

\section{Large interlayer spacing vanadium oxide nanotubes as cathodes for high performance sodium ion batteries $\uparrow$}

\begin{abstract}
Kun Zhang, Guohua Gao, (D) * Wei Sun, (D) Xing Liang, Yindan Liu and Guangming Wu*
Sodium ion batteries (SIBs), as a potential alternative to Li-ion batteries (LIBs), have attracted great attention from researchers. Herein, large interlayer spacing ferric ion substituted vanadium oxide nanotubes (FeVNTs) are fabricated using dodecylamine as a template via a facile hydrothermal treatment followed by a ferric ion substitution process. The distances between the adjacent layers of VNT, Fe-VNTs and orthorhombic $\mathrm{V}_{2} \mathrm{O}_{5}$ are $2.7 \mathrm{~nm}, 1.2 \mathrm{~nm}$ and $0.44 \mathrm{~nm}$, respectively. The larger interlamellar spacing results in faster $\mathrm{Na}^{+}$diffusion reaction kinetics, and the insertion of ferric ion into vanadium oxide layers removes the organic templates between the vanadium oxide layers, leading to high conductivity and small electrochemical reaction resistance. Serving as the sodium ion battery cathode, Fe-VNTs display enhanced sodium storage performance over orthorhombic $\mathrm{V}_{2} \mathrm{O}_{5}$.
\end{abstract}

\section{Introduction}

In the past decades, much attention has given to energy production and storage technologies. ${ }^{1,2}$ Lithium-ion batteries (LIBs), as one of the most important energy-storage technologies, are the main candidates for large-scale energy storage systems (ESSs). ${ }^{3,4}$ The increasing requirement for lithium may cause the price of lithium to skyrocket due to its low abundance and uneven distribution., Hence, the discovery of cheaper alternatives to replace lithium has attracted great interest., ${ }^{7,8}$ By virtue of the wide availability and lowcost of sodium resources, sodium-ion batteries (SIBs) have emerged as one of the promising substitutes for LIBs. ${ }^{9,10}$ Meanwhile, SIBs have a similar ion intercalation mechanism. ${ }^{\mathbf{1 1 , 1 2}}$

Vanadium oxides, with unique open-layered structures, are considered as one of the most promising electrode materials for electrochemical energy storage due to its high theoretical capacity, abundance resource and low cost. ${ }^{\mathbf{1 3 , 1 4}}$ Generally, the layered structures contain $\left[\mathrm{VO}_{6}\right]$ octahedral geometry and/or $\left[\mathrm{VO}_{5}\right]$ square pyramid with a long $\mathrm{V}-\mathrm{O}$ bond and a short vanadyl bond, $\mathrm{V}=\mathrm{O} .{ }^{15}$ Various vanadium oxide layered structures are formed and exhibit promising sodium storage performance. ${ }^{16-19}$ The crystal structure of orthorhombic $\mathrm{V}_{2} \mathrm{O}_{5}$ can be described as layers of $\mathrm{VO}_{5}$ square pyramids, with an interlayer spacing of $4.37 \AA$, exhibits the quite attractive electrochemical performance when used as cathode materials of LIBs. ${ }^{20-22}$ However, $\mathrm{Na}^{+}$ions (1.02 $⿱$ A) are larger compared to $\mathrm{Li}^{+}$ions $(0.76 \AA)$ resulting in the kinetically sluggish

Shanghai Key Laboratory of Special Artificial Microstructure Materials and Technology, School of Physics Science and Engineering, Tongji University, Shanghai, 200092, China.E-mail: gao@tongji.edu.cn;wugm@tongji.edu.cn

$\dagger$ Electronic supplementary information (ESI) available. See DOI: 10.1039/c8ra03514h of $\mathrm{Na}^{+}$insertion/extraction and low diffusion rate in the compact crystal structure. ${ }^{2324}$ Therefore, rational design of cathode materials with larger diffusion channels/suitable lattice space to host $\mathrm{Na}^{+}$ions and promote rapid $\mathrm{Na}^{+}$insertion and extraction are of great importance. To enhance $\mathrm{Na}$ storage performance via controlling the interlayer spacing has been recognized in few works. ${ }^{25-29}$ Wang et al. synthesized single-crystalline bilayered $\mathrm{V}_{2} \mathrm{O}_{5}$ nanobelts with large (001) interlayer spacing (11.53 $\mathrm{\AA}$ ) can accommodate $\mathrm{Na}^{+}$intercalation and deintercalation. ${ }^{26}$ Additionally, Mai et al. synthesized $\mathrm{V}_{2} \mathrm{O}_{5} \cdot \mathrm{nH}_{2} \mathrm{O}$ xerogel with water molecules intercalated into layer structure which can enlarge interlayer spacing and enhance high initial capacity. ${ }^{27}$

In this study, we successfully synthesize vanadium oxide nanotubes $\left(\mathrm{VO}_{x}\right.$-NTs) with super wide interlayer spacing using dodecylamine as templates through a simple hydrothermal treatment. Since organic templates do not possess good conductivity and will block the diffusion of $\mathrm{Na}^{+}$during the insertion-extraction. In order to improve the electrochemical performance, the following ferric ion substitution process was carried out to remove the organic template. This ferric ion substitution reaction can effectively remove the amine templates within $\mathrm{VO}_{x}$-NTs, and maintain their tubular morphology and multiwalled structure. It is expected that the as-synthesized ferric ion substituted vanadium oxide nanotubes $\left(\mathrm{Fe}-\mathrm{VO}_{x}-\mathrm{NTs}\right)$ may exhibited faster diffusion reaction kinetics, and accommodated larger volume changes, benefiting for the sodium storage.

\section{Experimental}

\subsection{Material preparation}

2.1.1 Synthesis of VNTs. Vanadium oxide nanotubes (VNTs) were prepared as following: $0.51 \mathrm{~g}$ of $\mathrm{V}_{2} \mathrm{O}_{5}$ powder and 
$0.52 \mathrm{~g}$ of dodecylamine $\left(\mathrm{C}_{12} \mathrm{H}_{25} \mathrm{NH}_{2}\right)$ were dissolved in $40 \mathrm{ml}$ distilled water under vigorous stirring for two days. The obtained solution was transferred to a $50 \mathrm{ml}$ Teflon lined autoclave and heated at $180{ }^{\circ} \mathrm{C}$ for 5 days in an oven and then cooled to room temperature naturally. The final product was filtered, washed with de-ionized (DI) water and pure alcohol several times and then dried at $70{ }^{\circ} \mathrm{C}$ in vacuum for $12 \mathrm{~h}$.

2.1.2 Synthesis of Fe-VNTs. $\mathrm{VO}_{x}$-NTs $\left(\begin{array}{lll}500 & \mathrm{mg}\end{array}\right)$ was dispersed in a mixture of distilled water and ethanol $(10 \mathrm{ml}$ and $80 \mathrm{ml}$ respectively) by sonication for $2 \mathrm{~h}$. Then, $5 \mathrm{~g}$ of $\mathrm{FeCl}_{3}$ $\cdot 6 \mathrm{H}_{2} \mathrm{O}$ was dissolved in $10 \mathrm{ml}$ of de-ionized (DI) water. After that, the $\mathrm{FeCl}_{3} \cdot 6 \mathrm{H}_{2} \mathrm{O}$ solution was slowly added into VNTs suspension and kept continuously stirring for $24 \mathrm{~h}$. The precipitate was filtered, rinsed, and dried under vacuum at $80{ }^{\circ} \mathrm{C}$ for $12 \mathrm{~h}$ to obtain Fe-VNTs.

For comparison, crystalline $\mathrm{V}_{2} \mathrm{O}_{5}$ powder was also employed as controlled group.

\subsection{Characterizations}

The morphology, structure and composition of the asprepared samples were analyzed by field emission scanning electron microscopy (FESEM, Philips-XL-30FEG) and transmission electron microscopy (TEM, JEOL-1230), X-ray powder diffraction (XRD) patterns were obtained by using a RigakuD/Max-c diffractometer with $\mathrm{Cu} \mathrm{K} \alpha$ radiation source $(\lambda=1.5406 \AA)$. Fourier transform infrared spectroscopy (FTIR) was measured using a Bruker-TENSOR27 FTIR spectrometer over the range from 400 to $4000 \mathrm{~cm}^{-1}$. The thermogravimetry analysis (TGA) and differential scanning calorimeter (DSC) were carried out on a SDT Q600 over the temperature range from 50 to $800{ }^{\circ} \mathrm{C}$ using a heating rate of $10{ }^{\circ} \mathrm{C} \min ^{-1}$ under air atmosphere. XPS experiments were carried out on a RBD upgraded PHI-5000C ESCA system (Perkin-Elmer) with $\mathrm{Mg} \mathrm{K} \alpha$ radiation $(h v=1253.6 \mathrm{eV})$. Binding energies were calibrated by using the containment carbon $(\mathrm{C} 1 \mathrm{~s}=284.6 \mathrm{eV})$.

\subsection{Battery assembly and electrochemical performance measurements}

The SIBs performance for the as-made samples was evaluated by using 2032-type coin cells with a voltage window of 1.5-3.5 V. The working electrodes were prepared by mixing $70 \mathrm{wt} \%$ active materials, $20 \mathrm{wt} \%$ carbon black as a conducting agent and $10 \mathrm{wt} \%$ poly (vinylidene fluoride) (PVDF) as a binder. $\mathrm{N}$-Methylpyrrolidone (NMP) solvent was added to the mixture to form a slurry, which was uniformly pasted on aluminum foils. The coated electrodes were dried in vacuum at $120^{\circ} \mathrm{C}$ for $10 \mathrm{~h}$ and then cut into disks. The coin cells can be assembled with a sodium metal slice, electrolyte $\left(1 \mathrm{M} \mathrm{NaClO}_{4}\right.$ in ethylene carbonate (EC) and diethyl carbonate (DEC) (volume ratio of $1: 1)$ with $5 \mathrm{wt} \%$ fluoroethylene carbonate (FEC) additive), a glass fiber separator (Whatman) and a slice of the as-made sample in Ar-filled dry glovebox. For comparison, crystalline $\mathrm{V}_{2} \mathrm{O}_{5}$ powder was also used as electrode to assemble 2032-type coin cells via similar procedures. Cyclic voltammograms (CV) were collected usingCHI660C (Chenghua, Shanghai) electrochemical workstation at a scan rate of $0.5 \mathrm{mV} \mathrm{s}^{-1}$. Galvanostatic charge/discharge tests were performed by using LAND celltesting system. An AC signal of $5 \mathrm{mV}$ was employed to measure electrochemical impedance spectra (EIS) within the

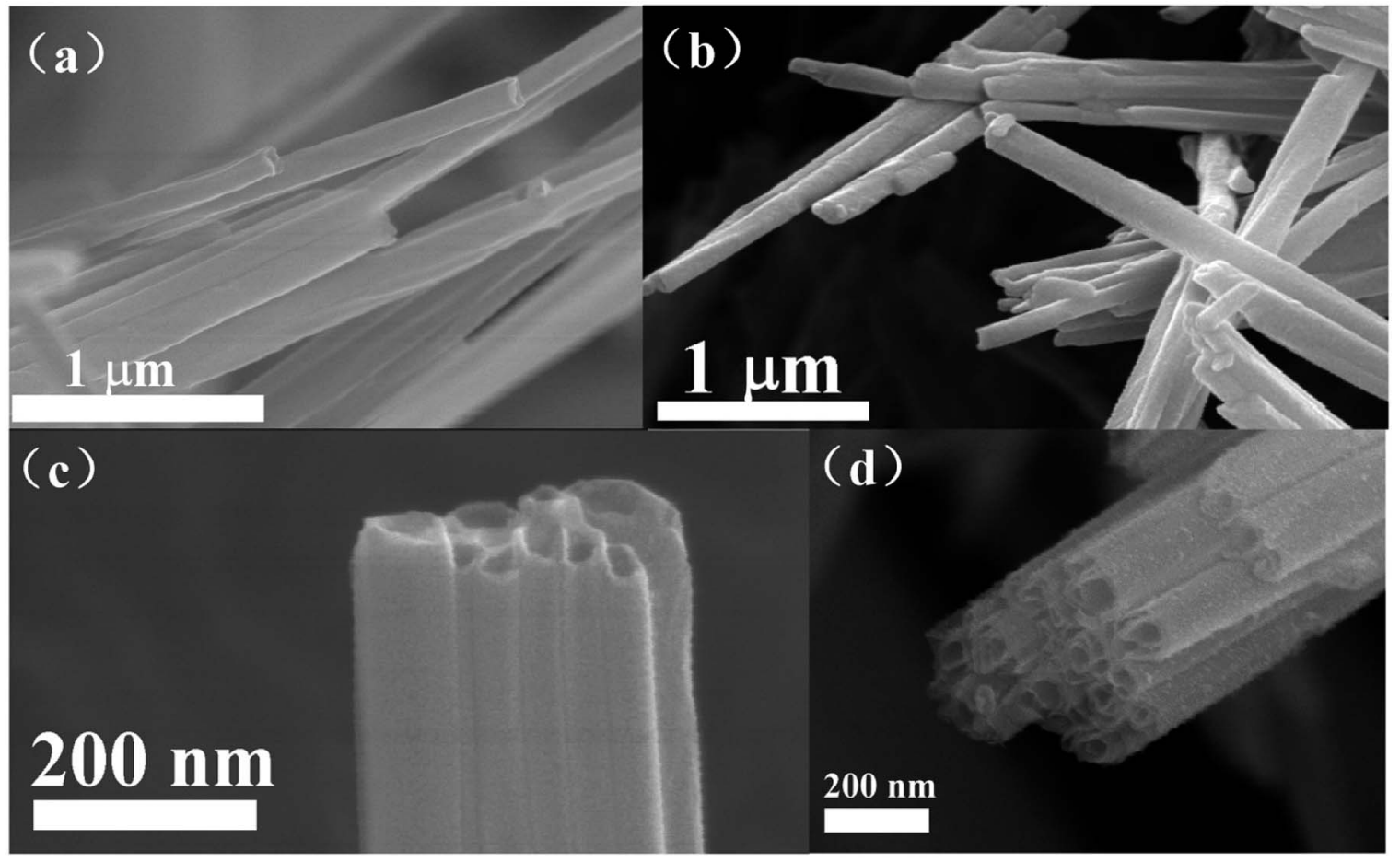

Fig. 1 Low- and high-magnification FE-SEM images of the (a and c) VNTs (b and d) Fe-VNTs. 
frequency range from $0.01 \mathrm{~Hz}$ to $100 \mathrm{kHz}$. All tests were carried out at the room temperature.

\section{Results and discussion}

Fig. 1 shows the FE-SEM images of $\mathrm{VO}_{x}$-NTs and $\mathrm{Fe}-\mathrm{VO}_{x}$-NTs. Clearly, both of the samples exhibit the hollow tubular structure with an diameter from 50 to $130 \mathrm{~nm}$. The tubular morphology of $\mathrm{VO}_{x}$-NTs are under preservation during ferric ions substitution process.

Fig. 2 repents the HRTEM images of $\mathrm{VO}_{x}$-NTs and Fe- $\mathrm{VO}_{x^{-}}$ NTs at different magnifications, respectively. Both two samples exhibit a well-defined multilayered structure with an openended tube. The Fe- $\mathrm{VO}_{x}$-NTs show larger inner diameter (50$80 \mathrm{~nm}$ ) than that of $\mathrm{VO}_{x}$-NTs $(30-50 \mathrm{~nm})$. The removal of ferric ion and Fig. $2 \mathrm{~b}$ shows the interlayer spacing of $\mathrm{VO}_{x}$-NTs are expanded to be $2.7 \mathrm{~nm}$ under dodecylamine embedding. The dark fringes are $\mathrm{VO}_{x}$ layers and the light fringes represent dodecylamine templates. To improve electrochemical performance, the removal of amine templates is necessary. As shown in Fig. 2d, the distance between $\mathrm{VO}_{x}$ layers within $\mathrm{Fe}-\mathrm{VO}_{x}$-NTs decreases obviously from 2.7 to $1.2 \mathrm{~nm}$, but the multiwalled tubular structure remain unaffected after this substitution reaction. With amine templates effectively removed, which can facilitate the sodium ions diffusion. Some nanoparticles are found in both samples. The high magnifications HRTEM image (Fig. S1†) clearly displays the lattice fringes with a spacing of $0.240 \mathrm{~nm}$ corresponding to the (401) plane of $\mathrm{V}_{2} \mathrm{O}_{5}$. Therefore, undissolved $\mathrm{V}_{2} \mathrm{O}_{5}$ would exist as nanoparticles due to the poor solubility in water.

The two samples are first characterized by X-ray diffraction (XRD). As can be seen from the XRD image, the typical (00l) diffraction at small-angle $\left(1-5^{\circ}\right)$ peaks in Fig. 3a, which are corresponding to the well-ordered layered structure of the tubular sample. ${ }^{30}$ The typical $(h k 0)$ diffraction peaks at wideangle $\left(5-50^{\circ}\right)$ in Fig. $3 \mathrm{~b}$ are ascribed to two-dimensional structure of $\mathrm{VO}_{x}$ layers. ${ }^{31}$ The (001) peak of Fe-VNT has shifted from $3.23^{\circ}$ to $7.37^{\circ}$ compared to that of VNT, indicating a decrease of interlayer spacing along c-axis after ferric ion substitution. The shrinkage of interlayer spacing results from the effective removal of dodecylamine templates. It can be calculated that the distance between adjacent layers are changed from 2.7 to $1.2 \mathrm{~nm}$, in agreement with the TEM results. The typical $(h k 0)$ diffraction peaks are at same position after ferric ion substitution process which indicate two-dimensional structure of $\mathrm{VO}_{x}$ layers remain unchanged.

Fig. 4 is the schematic illustration of the ferric ion substitution. For VNT, the protonated dodecylamine cations $\left(\mathrm{C}_{12} \mathrm{H}_{25} \mathrm{NH}_{3}{ }^{+}\right)$is positively charged and intercalates the negatively charged $\mathrm{VO}_{x}$ layers through electrostatic interaction. However, this interaction is broken, when more positively charged $\mathrm{Fe}^{3+}$ with smaller size insects into $\mathrm{VO}_{x}$ layers. Meanwhile, the organic templates are removed out of the $\mathrm{VO}_{x}$ layers and lead to the shrinkage of interlayer spacing. ${ }^{32}$

The TG-DSC curves of samples are showed in Fig. 5. The two samples undergo significant thermal weightlessness owing to

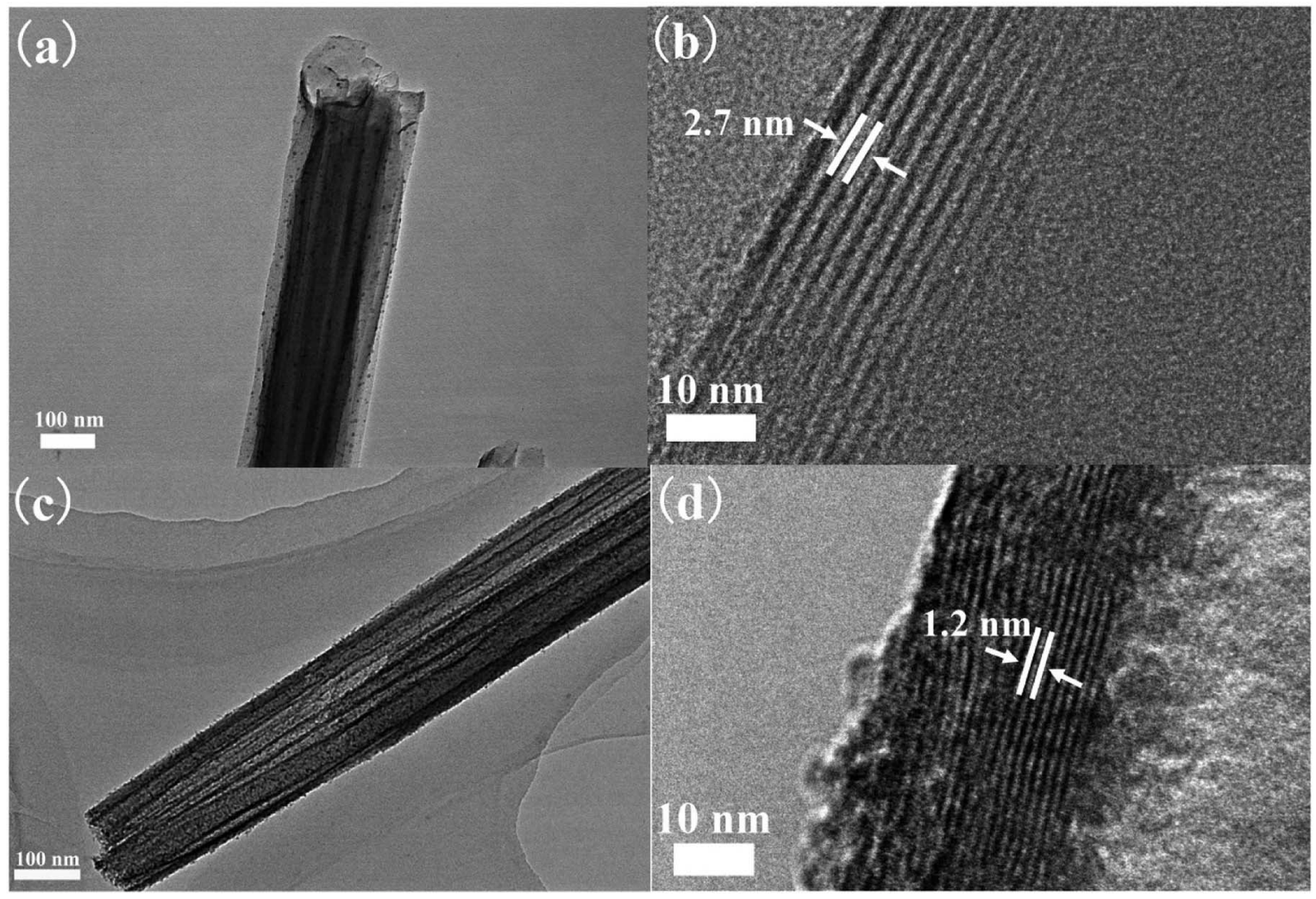

Fig. 2 TEM images of ( $a$ and b) VNTs (c and d) Fe-VNTs at different magnifications. 

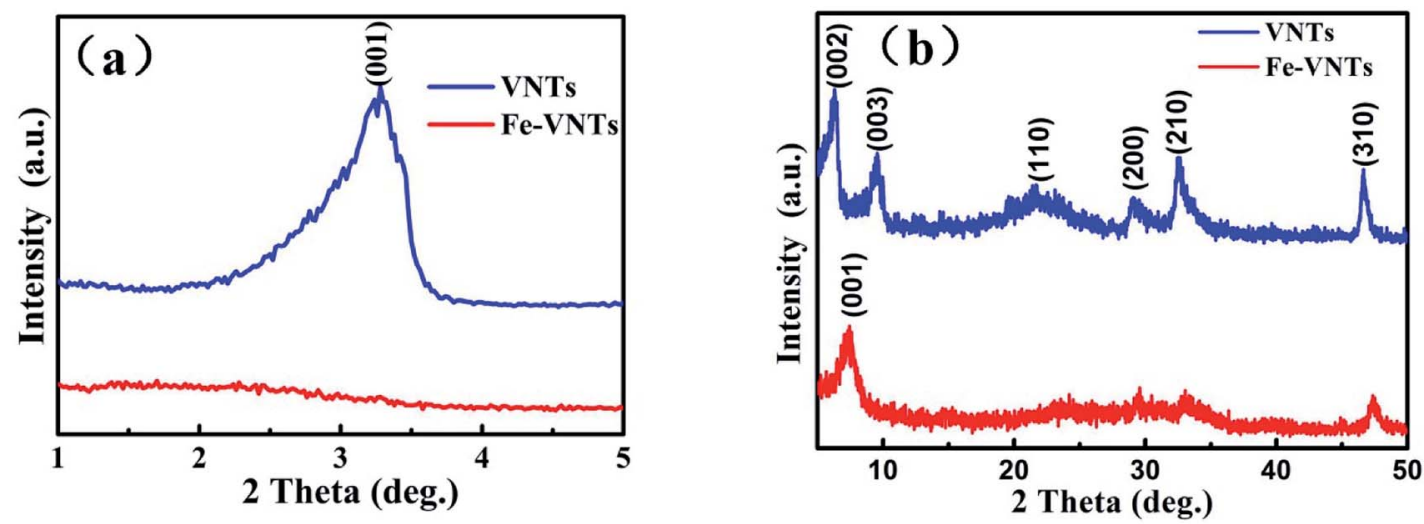

Fig. 3 Small-angle (a) and wide-angle (b) XRD patterns of VNTs and Fe-VNTs.

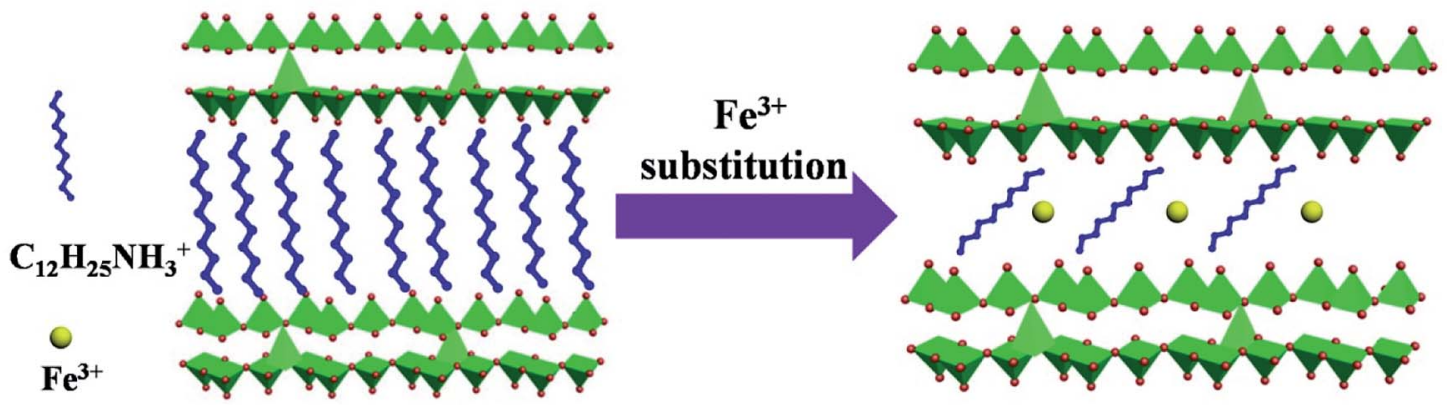

Fig. 4 Schematic illustration of the ferric ion substitution.
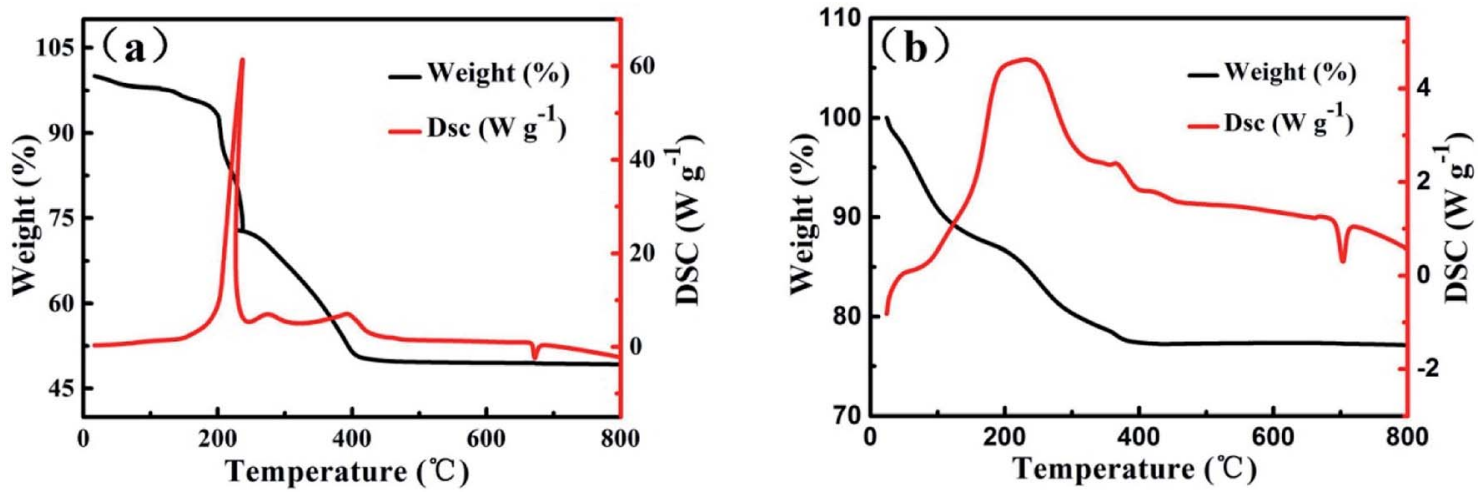

Fig. 5 The thermos-gravimetric analyses (TGA) of (a) VNTs (b) Fe-VNTs.

the decomposition of organic templates. The weight loss of $\mathrm{VO}_{x}-$

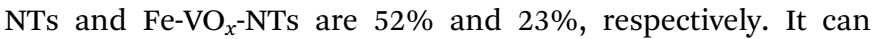
demonstrate that a large content of organic templates are removed by ferri ion substitution reaction. There are two endothermic peaks locate at $220{ }^{\circ} \mathrm{C}$ and $380{ }^{\circ} \mathrm{C}$ on DSC curve corresponding to the decomposition of dodecylamine and the crystallization of vanadium oxide, respectively.

The samples are further characterized by Fourier transform infrared (FTIR) spectra, X-ray photoelectron spectroscopy (XPS). For $\mathrm{VO}_{x}$-NTs, the peak at 575 and 797 and $1002 \mathrm{~cm}^{-1}$ are in Fig. 6 are corresponding to the vibrations of $\mathrm{O}-(\mathrm{V})_{3}$ bending,
$\mathrm{V}-\mathrm{O}-\mathrm{V}$ vibration and stretching vibration of $\mathrm{V}=\mathrm{O} .^{33,34}$ The absorption bands located at 2853 and $2927 \mathrm{~cm}^{-1}$ are attributed to the various $\mathrm{C}-\mathrm{H}$ vibrations in the organic templates. ${ }^{35}$ Both of the samples have the board peak at 1623 and $3445 \mathrm{~cm}^{-1}$ which are assigned to $\mathrm{H}-\mathrm{O}-\mathrm{H}$ bending vibration and $\mathrm{H}-\mathrm{O}$ stretching. ${ }^{33,36}$ Remarkably, there are some differences between two samples. The intensity of the peaks at $2927 \mathrm{~cm}^{-1}$ association with organic templates in $\mathrm{Fe}-\mathrm{VO}_{x}$-NTs has weakened significantly, and the peak at $2853 \mathrm{~cm}^{-1}$ disappears (inset figure of Fig. 6), which indicates large amount of templates are removed after ferric ion substitution. 


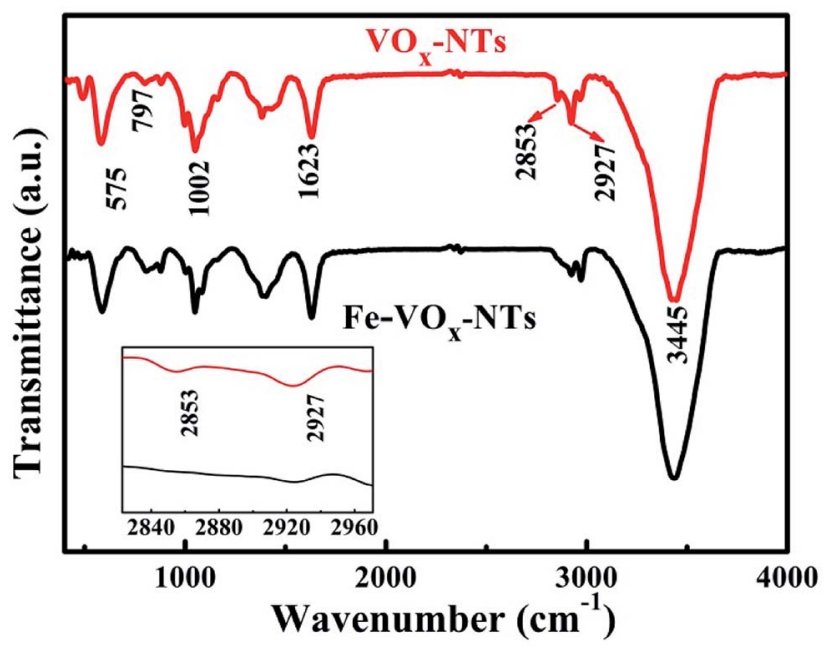

Fig. 6 FTIR spectra of VNTs and Fe-VNTs. Inset is the zoom area of two peaks located at 2835 and $2917 \mathrm{~cm}^{-1}$.

X-ray photoelectron spectroscopy (XPS) measurements is further performed to identify the elemental composition of two samples and study the valence change of vanadium. From XPS general spectra of VNTs and Fe-VNTs in Fig. 7a and b, the FeVNTs show weaker C1s peaks and new Fe2p peak which demonstrate the organic templates are effectively removed and the existence of ferric ions. The N1s peak corresponding to $-\mathrm{C}-$ $\mathrm{NH}_{2}$ group disappeared in Fig. 7b due to less organic templates within Fe-VNTs. The V2 $\mathrm{p}_{3 / 2}$ are comprised of two parts locating at the banding energy of 517.7 and $516.5 \mathrm{ev}$ which are consistent with the two formal reported values for $\mathrm{V}^{5+}$ and $\mathrm{V}^{4+} \cdot{ }^{37,38} \mathrm{The}^{5+}$ / $\mathrm{V}^{4+}$ ratio of VNT and Fe-VNT are 0.93 and 1.13 (Fig. 7c and d), respectively. The $\mathrm{V}^{5+}$ concentration in samples is increased after ferric ion substitution, which may caused by the $\mathrm{Fe}^{3+}$ ions. To further proved it, the spectra of Fe2p is involved (Fig. 8). The peak at $711.4 \mathrm{eV}$ is observed which is attributed to $\mathrm{Fe}^{2+}$ in addition to a strong peak at $712.7 \mathrm{eV}$ is ascribed to $\mathrm{Fe}^{3+} \cdot{ }^{39}$ The result indicates $\mathrm{Fe}^{3+}$ are partially reduced to $\mathrm{Fe}^{2+}$ in Fe-VNTs. It is clear that the strong oxidizing $\mathrm{Fe}^{3+}$ has oxidized some $\mathrm{V}^{4+}$ into $\mathrm{V}^{5+}$ which cause the appearance of $\mathrm{Fe}^{2+}$. Furthermore, the atomic ratio of $\mathrm{Fe} / \mathrm{V}$ is $0.053 / 1$, which was figured out by inductively coupled plasma (ICP) analysis.

Electrochemical performance of two samples are evaluated as an cathode material for NIBs by assembling the coin cell (2032-type). Fig. 9a shows the initial charge-discharge curves in 1.5-3.5 $\mathrm{V}$ at current density of $50 \mathrm{~mA} \mathrm{~g}^{-1}$. Both VNTs and FeVNTs exhibit smooth charge and discharge without obvious discharge plateau, manifesting amorphous features. ${ }^{17}$ The VNTs show a low first discharge specific capacity of $138 \mathrm{~mA} \mathrm{~h} \mathrm{~g}^{-1}$. By contrast, the Fe-VNTs deliver a higher discharge specific capacity of $185 \mathrm{~mA} \mathrm{~h} \mathrm{~g}^{-1}$. This might due to
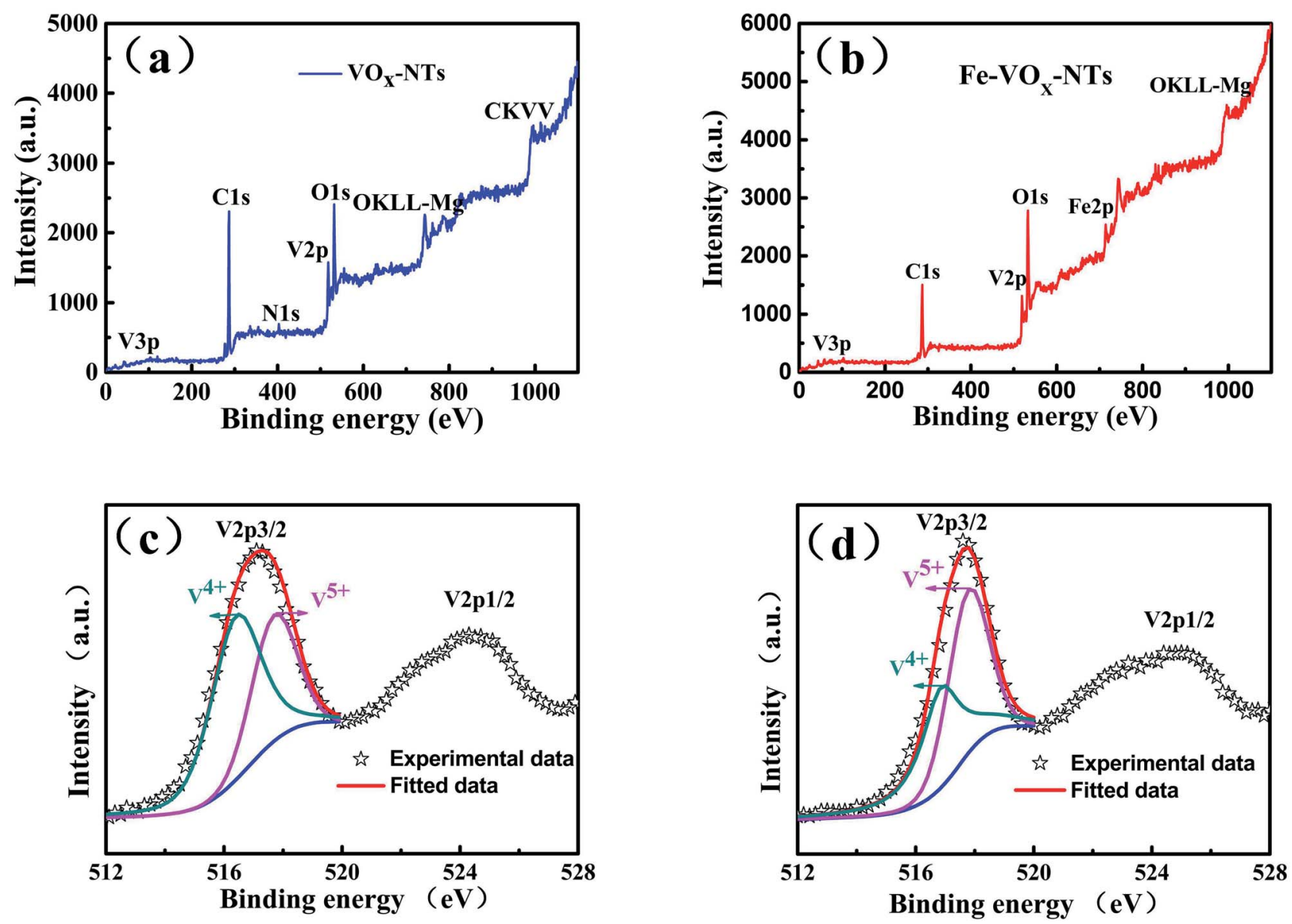

Fig. 7 XPS general spectrum (a) and V2p region (c) of the VNTs, and XPS general spectrum (b) and V2p region (d) of the Fe-VNTs. 


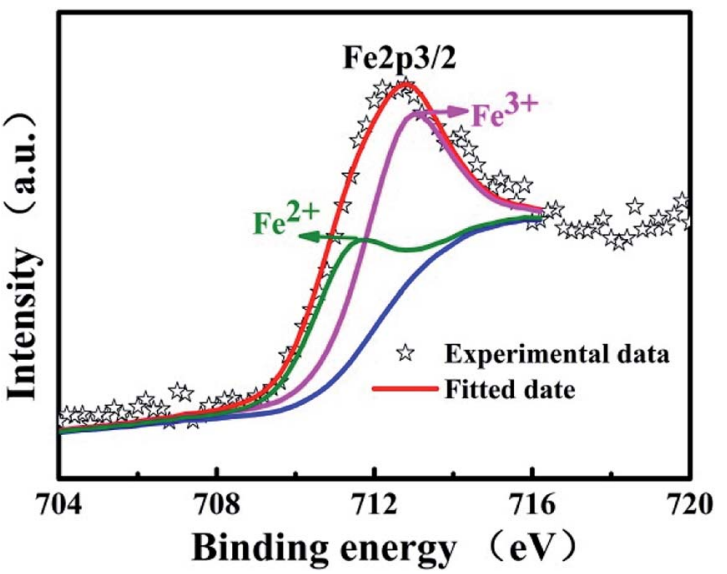

Fig. 8 XPS spectrum of Fe2p.

the release of organic templates and the preintercalation of ferric ion. While the orthorhombic $\mathrm{V}_{2} \mathrm{O}_{5}$ exhibits lowest discharge capacity of $76 \mathrm{~mA} \mathrm{~h} \mathrm{~g}{ }^{-1}$ and worst reversible discharge capacity (Fig. S1 $\dagger$ ), originating from its compact crystal structure which may causes the slow sodium ion diffusion. Cyclic voltammetry (CV) (Fig. 9b) were carried out at a scan rate of $0.5 \mathrm{mV} \mathrm{s}^{-1}$. Different from VNT which has no pronounced peaks (Fig. S3 $\dagger$ ), one cathodic peak at $\sim 2.07 \mathrm{~V}$ and a pair of anodic peaks at $\sim 2.61,2.98 \mathrm{~V}$ appear in the $\mathrm{CV}$ curves of Fe-VNTs. Larger surrounded area of the Fe-VNTs demonstrates higher capacity and faster kinetic during electrochemical insertion/extraction than those of VNTs. Fig. 10 shows cycling performance of the samples at different discharge current density of 50 and $80 \mathrm{~mA} \mathrm{~g}^{-1}$. After 50 cycles at $50 \mathrm{~mA} \mathrm{~g}^{-1}$ (Fig. 10a), the Fe-VNTs deliver a discharge specific capacity of $70 \mathrm{~mA} \mathrm{~g}^{-1}$ which is higher than $25 \mathrm{~mA} \mathrm{~g}^{-1}$ of VNTs. Fe-VNTs have a better cycling performance than VNTs. The cycling performance of orthorhombic $\mathrm{V}_{2} \mathrm{O}_{5}$ has shown in Fig. $\mathrm{S} 2, \uparrow$ the second discharge specific capacity drops from 76 to $11 \mathrm{~mA} \mathrm{~h} \mathrm{~g}^{-1}$ and remain below $10 \mathrm{~mA} \mathrm{~h} \mathrm{~g}{ }^{-1}$ in the following cycling. The small interlayer spacing hinder the insertion/extraction of $\mathrm{Na}^{+34}$
It is excepted that VNTs show better electrochemical performance than Fe-VNTs due to its larger interlayer spacing which allow more $\mathrm{Na}^{+}$to insert. However, large amount amine templates within VNTs will impede the diffusion of $\mathrm{Na}^{+}$. It can demonstrate the ferric ion substitution process facilitate electrochemical capacity and cycling performance.

To understand the increased electrochemical performance of Fe-VNTs, the electrochemical impedance spectra (EIS) were measured (Fig. 11a). The Nyquist plots consist of a compressed semicircle in the high-frequency region, which related to the charge transfer resistance $\left(R_{\mathrm{ct}}\right)$ of the electrode, and a sloped line in the low frequency region which corresponds to the Warburg impendence $\left(W_{\mathrm{o}}\right)$. In this equivalent circuit, $R_{\mathrm{e}}$ stands for all ohmic resistance, including the electrolyte and other part of the system. $R_{\mathrm{ct}}$ represents the charge-transfer impedance at the electrode/electrolyte interface. CPE and $W_{\mathrm{o}}$ are constant phase-angle element and Warburg impedance, respectively. The $R_{\text {ct }}$ value of VNT is $1589.9 \Omega$ and that of Fe-VNTs is $337.7 \Omega$. By contrast, the orthorhombic $\mathrm{V}_{2} \mathrm{O}_{5}$ delivers the $R_{\mathrm{ct}}$ value of $2325 \Omega$ (Fig. S3 $\dagger$ ). Obviously, it demonstrates that Fe-VNTs possesses faster kinetics of electrochemical reaction and higher capacity, which owe to its large interlayer spacing boosting sodium insertion/extraction. The sodium ion diffusion coefficient value $(D)$ is proportional to the reciprocal of squared value of Warburg factor $\sigma\left(D_{\mathrm{Na}} \propto 1 / \sigma^{2}\right){ }^{40-42} \sigma$ is relative to $Z_{\mathrm{re}}$. From the slop of the lines in Fig. $11 \mathrm{~b} \sigma$ can be obtained. ${ }^{43}$

$$
Z_{\mathrm{re}}=R_{\mathrm{D}}+R_{\mathrm{L}}+\sigma \omega^{-1 / 2}
$$

$\mathrm{Na}^{+}$diffusion coefficient at room temperature can be indirectly evaluate by calculating $\sigma$ values. As calculated, $\sigma$ value of Fe-VNTs is 167 which is lower than 654 of VNT, indicating the Fe-VNTs possess better $\mathrm{Na}^{+}$diffusion. The increase of sodium ion diffusion coefficient results from the release of organic templates which facilitate $\mathrm{Na}^{+}$intercalation. To be specific, it can provides more open channels for facile $\mathrm{Na}^{+}$intercalation and deintercalation. As discussed above, enhancement electrochemical performance of Fe-VNTs can be well explained by ferric ion substitution.
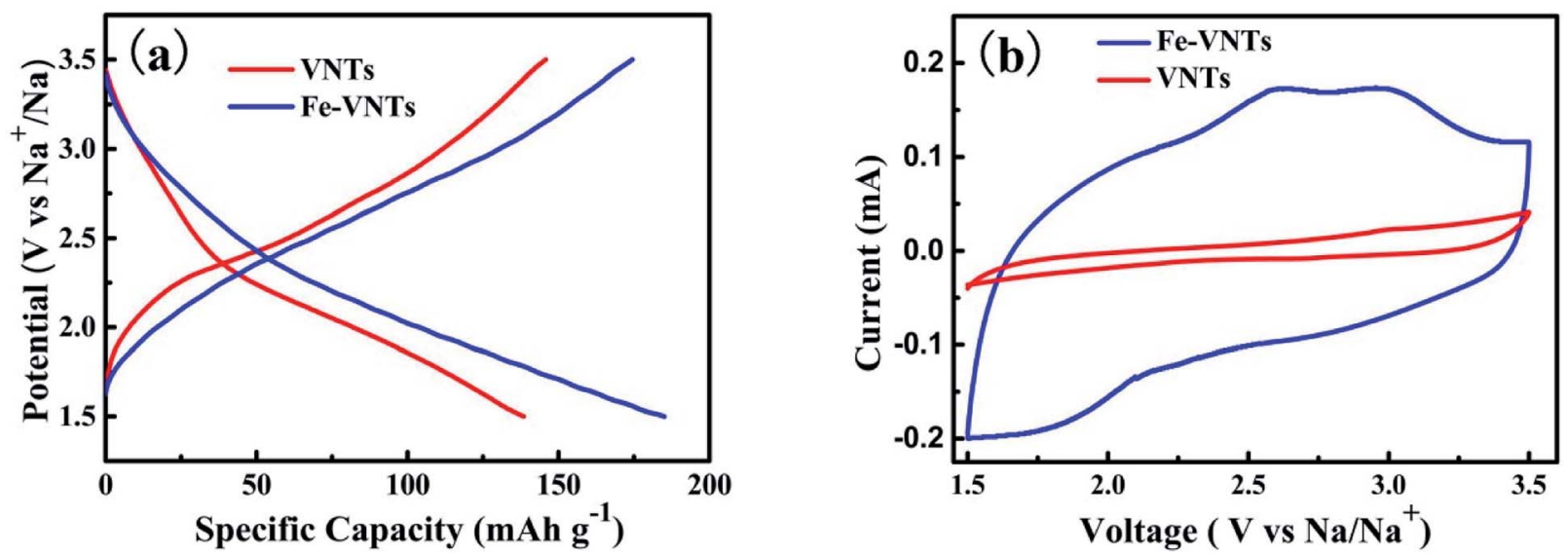

Fig. 9 (a) Galvanostatic charge-discharge profiles of first cycle of VNTs and Fe-VNTs between 1.5-3.5 V at $50 \mathrm{~mA} \mathrm{~g}^{-1}$. (b) Cyclic voltammograms of VNTs and Fe-VNTs at scan rate of $0.5 \mathrm{mV} \mathrm{s}^{-1}$. 

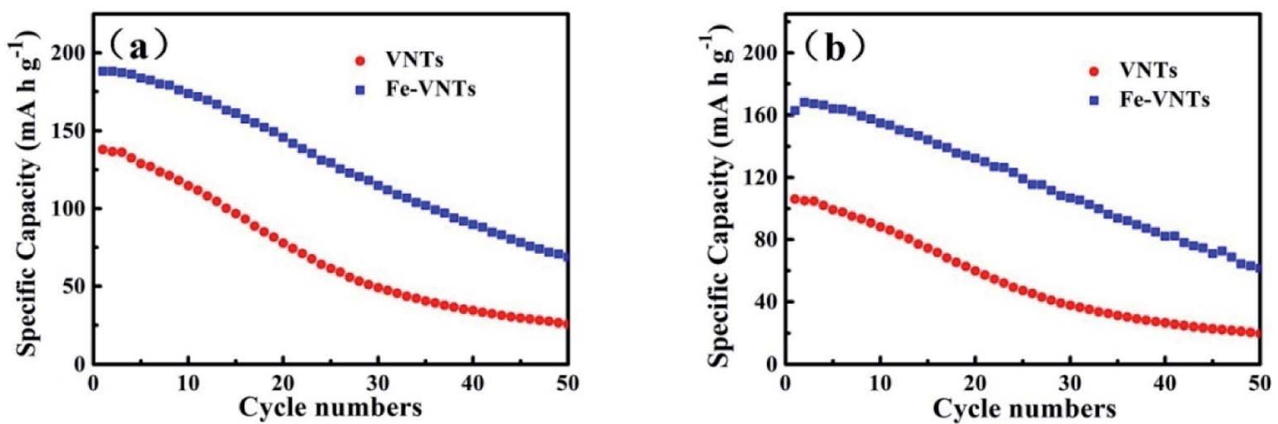

Fig. 10 Cycling performance of VNT and Fe-VNT at (a) $50 \mathrm{~mA} \mathrm{~g}^{-1}$ (b) $80 \mathrm{~mA} \mathrm{~g}^{-1}$
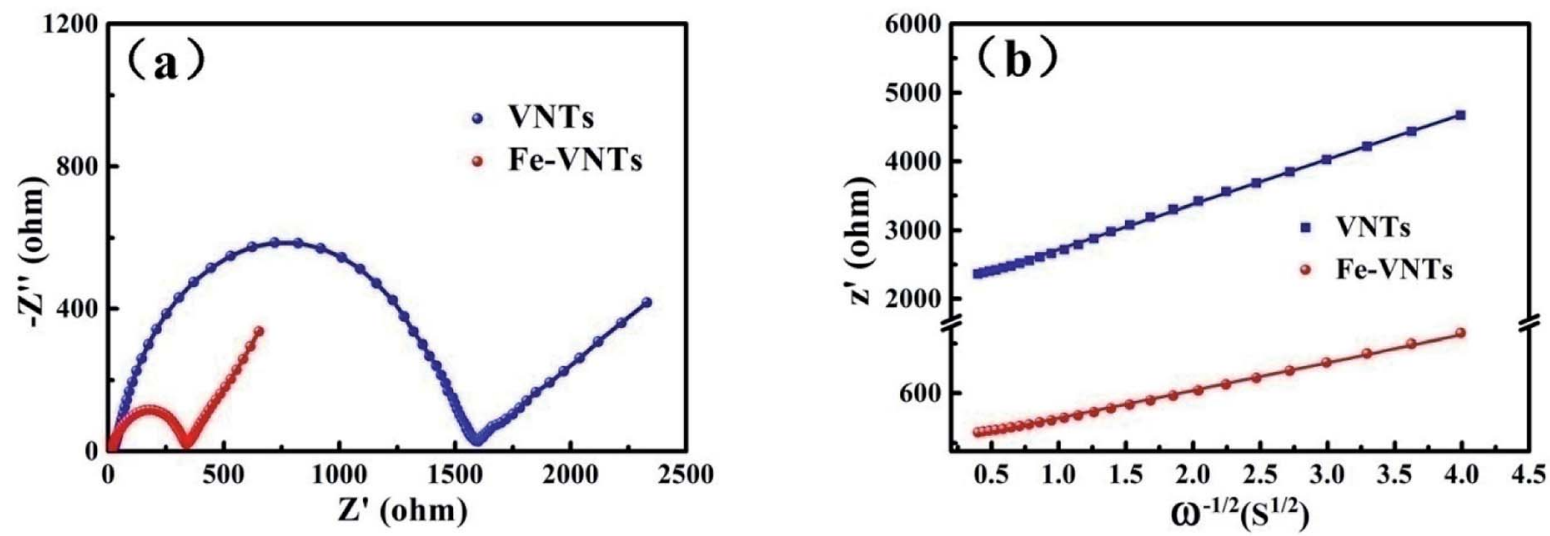

Fig. 11 (a) Nyquist plots of VNTs and Fe-VNTs. (b) The fitted lines and real part of the impedance versus $\omega^{-1 / 2}$ for VNTs and Fe-VNTs.

\section{Conclusions}

The Fe-VNTs were prepared by a facile hydrothermal treatment and followed by ion substitution process. With the ferric ion preintercalation, the interlayer spacing is reduced from 2.7 to $1.2 \mathrm{~nm}$. The enhanced electrochemical performance of Fe-VNTs are mainly attributed to the reasons as the following: (i) the organic templates which have no electrochemical contribution are effectively removed with its morphology and structure remain. (ii) The insertion of ferric ion lead to enhanced electronic conductivity and good charger transfer ability for reversible sodium storage capacity. (iii) The large interlayer space between Fe-VNTs can facility the kinetics of sodium ion intercalation/deintercalation. The novel ferric ion substituted vanadium oxide nanotubes demonstrate a great potential as cathode material for $\mathrm{Na}^{+}$ion batteries application.

\section{Conflicts of interest}

There are no conflicts to declare.

\section{Acknowledgements}

The author acknowledge the support of National Nature Science Foundation of China (Granted No. U1503292, No. 51472182), the Fundamental Research Funds for Central Universities, and the National Key Research and Development Program of China (Grant No. 2017YFA0204600).

\section{References}

1 J. Y. Hwang, S. T. Myung and Y. K. Sun, Sodium-ion batteries: present and future, Chem. Soc. Rev., 2017, 46(12), 3529-3614.

2 Y. Luo, M. S. Balogun, W. Qiu, R. Zhao, P. Liu and Y. Tong, Sulfurization of $\mathrm{FeOOH}$ nanorods on a carbon cloth and their conversion into $\mathrm{Fe}_{2} \mathrm{O}_{3} / \mathrm{Fe}_{3} \mathrm{O}_{4}$-S core-shell nanorods for lithium storage, Chem. Commun., 2015, 51(65), 13016-13019.

3 T. Jin, Q. Han, Y. Wang and L. Jiao, 1D Nanomaterials: Design, Synthesis, and Applications in Sodium-Ion Batteries, Small, 2018, 14(2), 1703086.

4 H. G. Wang, W. Li, D. P. Liu, X. L. Feng, J. Wang, X. Y. Yang, X. B. Zhang, Y. Zhu and Y. Zhang, Flexible Electrodes for Sodium-Ion Batteries: Recent Progress and Perspectives, Adv. Mater., 2017, 29(45), 1703012.

5 D. Larcher and J. M. Tarascon, Towards greener and more sustainable batteries for electrical energy storage, Nat. Chem., 2015, 7(1), 19-29.

6 H. W. Lee, R. Y. Wang, M. Pasta, S. Woo Lee, N. Liu and Y. Cui, Manganese hexacyanomanganate open framework as a high-capacity positive electrode material for sodiumion batteries, Nat. Commun., 2014, 5, 5280. 
7 Z. Dai, U. Mani, H. T. Tan and Q. Yan, Advanced Cathode Materials for Sodium-Ion Batteries: What Determines Our Choices, Small Methods, 2017, 1(5), 1700098.

8 N. Yabuuchi, M. Kajiyama, J. Iwatate, H. Nishikawa, S. Hitomi, R. Okuyama, R. Usui, Y. Yamada and S. Komaba, P2-type $\mathrm{Na}_{(x)}\left[\mathrm{Fe}_{(1 / 2)} \mathrm{Mn}_{(1 / 2)}\right] \mathrm{O}_{2}$ made from earthabundant elements for rechargeable $\mathrm{Na}$ batteries, Nat. Mater., 2012, 11(6), 512-517.

9 E. De la Llave, V. Borgel, K. J. Park, J. Y. Hwang, Y. K. Sun, P. Hartmann, F. F. Chesneau and D. Aurbach, Comparison between Na-Ion and Li-Ion Cells: Understanding the Critical Role of the Cathodes Stability and the Anodes Pretreatment on the Cells Behavior, ACS Appl. Mater. Interfaces, 2016, 8(3), 1867-1875.

10 P. Liu, K. Zhu, Y. Gao, H. Luo and L. Lu, Recent Progress in the Applications of Vanadium-Based Oxides on Energy Storage: from Low-Dimensional Nanomaterials Synthesis to 3D Micro/Nano-Structures and Free-Standing Electrodes Fabrication, Adv. Energy Mater., 2017, 7(23), 1700547.

11 J. Mei, T. Liao, L. Kou and Z. Sun, Two-Dimensional Metal Oxide Nanomaterials for Next-Generation Rechargeable Batteries, Adv. Mater., 2017, 29(48), 1700176.

12 S. P. Ong, V. L. Chevrier, G. Hautier, A. Jain, C. Moore, S. Kim, X. Ma and G. Ceder, Voltage, stability and diffusion barrier differences between sodium-ion and lithium-ion intercalation materials, Energy Environ. Sci., 2011, 4(9), 3680-3688.

13 D. McNulty, D. N. Buckley and C. O'Dwyer, Synthesis and electrochemical properties of vanadium oxide materials and structures as Li-ion battery positive electrodes, J. Power Sources, 2014, 267(4), 831-873.

14 Y. Li, J. Yao, E. Uchaker, J. Yang, Y. Huang, M. Zhang and G. Cao, Leaf-Like $\mathrm{V}_{2} \mathrm{O}_{5}$ Nanosheets Fabricated by a Facile Green Approach as High Energy Cathode Material for Lithium-Ion Batteries, Adv. Energy Mater., 2013, 3(9), 11711175.

15 N. A. Chernova, M. Roppolo, A. C. Dillon and M. S. Whittingham, Layered vanadium and molybdenum oxides: batteries and electrochromics, J. Mater. Chem. A, 2009, 19(17), 2526-2552.

16 B. Yan, X. Li, Z. Bai, L. Lin, G. Chen, X. Song, D. Xiong, D. Li and $\mathrm{X}$. Sun, Superior sodium storage of novel $\mathrm{VO}_{2}$ nanomicrospheres encapsulated into crumpled reduced graphene oxide, J. Mater. Chem. A, 2017, 5, 4850-4860.

17 E. Uchaker, Y. Z. Zheng, S. Li, S. L. Candelaria, S. Hu and G. Z. Cao, Better than crystalline: amorphous vanadium oxide for sodium-ion batteries, J. Mater. Chem. A, 2014, 2(43), 18208-18214.

18 X. Xu, C. Niu, M. Duan, X. Wang, L. Huang, J. Wang, et al., Alkaline earth metal vanadates as sodium-ion battery anodes, Nat. Commun., 2017, 8(1), 460.

19 S. Hartung, N. Bucher, J. B. Franklin, A. M. Wise, L. Y. Lim, H. Chen, et al., Mechanism of $\mathrm{Na}^{+}$insertion in alkali vanadates and its influence on battery performance, $A d v$. Energy Mater., 2016, 6(9), 1502336.

20 D. W. Su, S. X. Dou and G. X. Wang, Hierarchical orthorhombic $\mathrm{V}_{2} \mathrm{O}_{5}$ hollow nanospheres as high performance cathode materials for sodium-ion batteries, $J$. Mater. Chem. A, 2014, 2(29), 11185-11194.

21 Y. Liu, M. Clark, Q. Zhang, D. Yu, D. Liu, J. Liu and G. Cao, $\mathrm{V}_{2} \mathrm{O}_{5}$ Nano-Electrodes with High Power and Energy Densities for Thin Film Li-Ion Batteries, Adv. Energy Mater., 2011, 1(2), 194-202.

22 Y. Ma, A. Huang, H. Zhou, S. Ji, S. Zhang, R. Li, H. Yao, X. Cao and P. Jin, Template-free formation of various $\mathrm{V}_{2} \mathrm{O}_{5}$ hierarchical structures as cathode materials for lithium-ion batteries, J. Mater. Chem. A, 2017, 5(14), 6522-6531.

23 X. Zuo, Y. Xia, Q. Ji, X. Gao, S. Yin, M. Wang, X. Wang, B. Qiu, A. Wei, Z. Sun, Z. Liu, J. Zhu and Y. J. Cheng, Self-Templating Construction of 3D Hierarchical Macro-/Mesoporous Silicon from 0D Silica Nanoparticles, ACS Nano, 2017, 11(1), 889899.

24 X. Wang, K. Chen, G. Wang, X. Liu and H. Wang, Rational Design of Three-Dimensional Graphene Encapsulated with Hollow FeP@Carbon Nanocomposite as Outstanding Anode Material for Lithium Ion and Sodium Ion Batteries, ACS Nano, 2017, 11(11), 11602-11616.

25 S. Li, X. Li, Y. Li, B. Yan, X. Song and D. Li, Superior Sodium Storage of Vanadium Pentoxide Cathode with Controllable Interlamellar Spacing, Electrochim. Acta, 2017, 244, 77-85.

$26 \mathrm{D}$. Su and G. Wang, Single-Crystalline Bilayered $\mathrm{V}_{2} \mathrm{O}_{5}$ Nanobelts for High-Capacity Sodium-Ion Batteries, ACS Nano, 2013, 7(12), 11218-11226.

27 Q. Wei, J. Liu, W. Feng, J. Sheng, X. Tian, L. He, Q. An and L. Mai, Hydrated vanadium pentoxide with superior sodium storage capacity, J. Mater. Chem. A, 2015, 3(15), 8070-8075.

28 S. Tepavcevic, H. Xiong, V. R. Stamenkovic, X. Zuo, M. Balasubramanian, V. B. Prakapenka, C. S. Johnson and a. T. Rajh, Nanostructured Bilayered Vanadium Oxide Electrodes for Rechargeable Sodium-Ion Batteries, ACS Nano, 2011, 6(1), 530-538.

29 Q. Wei, Z. Jiang, S. Tan, et al., Lattice Breathing Inhibited Layered Vanadium Oxide Ultrathin Nanobelts for Enhanced Sodium Storage, ACS Appl. Mater. Interfaces, 2015, 7(33), 18211-18217.

30 J. Li, L.-F. Zheng, K.-F. Zhang, X.-Q. Feng, Z.-X. Su and J.-T. Ma, Synthesis of Ag modified vanadium oxide nanotubes and their antibacterial properties, Mater. Res. Bull., 2008, 43(10), 2810-2817.

31 F. Sediri and N. Gharbi, Nanorod B phase $\mathrm{VO}_{2}$ obtained by using benzylamine as a reducing agent, Mater. Sci. Eng., B, 2007, 139(1), 114-117.

32 X. Zhou, G. Wu, G. Gao, J. Wang, H. Yang, J. Wu, J. Shen, B. Zhou and Z. Zhang, Electrochemical Performance Improvement of Vanadium Oxide Nanotubes as Cathode Materials for Lithium Ion Batteries through Ferric Ion Exchange Technique, J. Phys. Chem. C, 2012, 116(41), 21685-21692.

$33 \mathrm{H}$. H. Kristoffersen and H. Metiu, Structure of $\mathrm{V}_{2} \mathrm{O}_{5} \cdot n \mathrm{H}_{2} \mathrm{O}$ Xerogels, J. Phys. Chem. C, 2016, 120(7), 3986-3992.

34 W. Chen, J. Peng, L. Mai, Q. Zhu and Q. Xu, Synthesis of vanadium oxide nanotubes from $\mathrm{V}_{2} \mathrm{O}_{5}$ sols, Mater. Lett., 2004, 58(17), 2275-2278. 
35 M. Malta, G. Louarn, N. Errien and R. M. Torresi, Redox behavior of nanohybrid material with defined morphology: Vanadium oxide nanotubes intercalated with polyaniline, $J$. Power Sources, 2006, 156(2), 533-540.

36 V. Palomares, Structural evolution of mixed valent $\left(\mathrm{V}^{3+} / \mathrm{V}^{4+}\right)$ and $\mathrm{V}^{4+}$ sodium vanadium fluorophosphates as cathodes in sodium-ion batteries: Comparisons, overcharging and mid-term cycling, J. Mater. Chem. A, 2015, 3(45), 2301723027.

37 X. Peng, X. Zhang, L. Wang, L. Hu, S. H.-S. Cheng, C. Huang, B. Gao, F. Ma, K. Huo and P. K. Chu, Hydrogenated $\mathrm{V}_{2} \mathrm{O}_{5}$ Nanosheets for Superior Lithium Storage Properties, Adv. Funct. Mater., 2016, 26(5), 784-791.

38 T. Zhai, X. Lu, Y. Ling, M. Yu, G. Wang, T. Liu, C. Liang, Y. Tong and Y. Li, A new benchmark capacitance for supercapacitor anodes by mixed-valence sulfur-doped $\mathrm{V}_{6} \mathrm{O}_{(13-x)}$, Adv. Mater., 2014, 26(33), 5869-5875.

39 M. C. Biesinger, B. P. Payne, A. P. Grosvenor, L. W. M. Lau, A. R. Gerson and R. S. C. Smart, Resolving surface chemical states in XPS analysis of first row transition metals, oxides and hydroxides: $\mathrm{Cr}, \mathrm{Mn}, \mathrm{Fe}, \mathrm{Co}$ and $\mathrm{Ni}$, Appl. Surf. Sci., 2011, 257(7), 2717-2730.

40 Y. Shi, J. Z. Wang, S. L. Chou, D. Wexler, H. J. Li, K. Ozawa, H. K. Liu and Y. P. Wu, Hollow structured $\mathrm{Li}_{3} \mathrm{VO}_{4}$ wrapped with graphene nanosheets in situ prepared by a one-pot template-free method as an anode for lithium-ion batteries, Nano Lett., 2013, 13(10), 4715-4720.

41 S.-L. Chou, J.-Z. Wang, H.-K. Liu and S.-X. Dou, Rapid Synthesis of $\mathrm{Li}_{4} \mathrm{Ti}_{5} \mathrm{O}_{12}$ Microspheres as Anode Materials and Its Binder Effect for Lithium-Ion Battery, J. Phys. Chem. C, 2011, 115(32), 16220-16227.

42 X. Zhou, G. Wu, J. Wu, H. Yang, J. Wang, G. Gao, R. Cai and Q. Yan, Multiwalled carbon nanotubes $-\mathrm{V}_{2} \mathrm{O}_{5}$ integrated composite with nanosized architecture as a cathode material for high performance lithium ion batteries, $J$. Mater. Chem. A, 2013, 1(48), 15459-15468.

43 P. Hu, M. Yan, X. Wang, C. Han, L. He, X. Wei, C. Niu, K. Zhao, X. Tian, Q. Wei, Z. Li and L. Mai, Single-Nanowire Electrochemical Probe Detection for Internally Optimized Mechanism of Porous Graphene in Electrochemical Devices, Nano Lett., 2016, 16(3), 1523-1529. 